\title{
Left Atrium Dilatation and Multiple Vascular Territory Strokes
}

\author{
Marie-Sarah Gagne Brosseau, Jean-Martin Boulanger, Nancy Leblanc, \\ Leo Berger, Micheal Benzazon
}

\begin{abstract}
Background: Atrial fibrillation (AF) is a cause of ischemic stroke and is associated with recurrence and with acute multivessel territory non lacunar stroke. Many cryptogenic strokes could be secondary to undiagnosed paroxystic AF. As left atrium (LA) dilatation is a risk factor of AF, we sought to determine if moderate or severe LA dilatation was associated with multiple vascular territory infarcts on magnetic resonance imaging (MRI) in patients with acute ischemic stroke without known AF. Normal LA diameter values are $\leq 4.0 \mathrm{~cm}$ for men and $\leq 3.8$ for women. Methods: Patients who presented at our center between 2006 and 2011 with a diagnosis of acute ischemic stroke (AIS) or transient ischemick attack (TIA) who had a transthoracic echocardiography and a brain MRI were included. Patients with known or de novo AF diagnosed within 3 months of the event were excluded. The main outcome was the presence of acute multi-vessel territory infarct(s) on MRI. Results: 356 patients were included. The mean LA diameter was 37 mm in the control group (normal or mildly dilated LA) and $49 \mathrm{~mm}$ in those with moderately to severely enlarged LA ( $<<0.001$ ). More patients in the LA dilatation group met the main outcome ( $20 \%$ vs $6 \%$; OR 3.89; $95 \%$ CI 1.32-11.43; $\mathrm{p}=0.0014)$. Conclusions: LA dilatation (at least moderate) is associated with acute non lacunar multiple vascular territory infarcts on MRI in patients with AIS or TIA without known AF or a confirmed diagnosis of AF. Further studies are necessary to determine if this population might benefit from anticoagulation therapy.
\end{abstract}

RÉSUMÉ: Dilatation de l'oreillette gauche et AVC dans plusieurs territoires vasculaires. Contexte: La fibrillation auriculaire (FA) est une cause d'accidents vasculaires cérébraux ischémiques qui est associée à la récidive et aux AVC non lacunaires dans de multiples territoires vasculaires. De nombreux AVC cryptogéniques pourraient être secondaires à des FA paroxystiques non diagnostiquées. Considérant que la dilatation de l'oreillette gauche (OG) est un facteur de risque de FA, nous avons cherché à déterminer au moyen de l'imagerie par résonance magnétique (IRM) si une dilatation modérée ou sévère de l'OG était associée à des infarctus dans de multiples territoires vasculaires chez des patients ayant un AVC ischémique aigu sans FA connue. Le diamètre normal de l'OG est $\leq 4,0 \mathrm{~cm}$ chez les hommes et $\leq 3,8 \mathrm{chez}$ les femmes. Méthodes: Des patients qui s'étaient présentés dans notre centre entre 2006 et 2011 avec un diagnostic d'AVC ischémique aigu ou d'accident ischémique transitoire (AIT) ont été inclus s'ils avaient eu une échocardiographie transthoracique et une IRM du cerveau. Les patients ayant une FA connue ou nouvellement diagnostiquée au cours des trois mois précédant l'événement ont été exclus. Le critère d'évaluation principale était la présence à l'IRM d'infarctus aigu dans le territoire de multiples vaisseaux. Résultats: Un total de 356 patients a été inclus. Le diamètre moyen de l'OG était de $37 \mathrm{~mm}$ dans le groupe témoin (OG normale ou légèrement dilatée) et de $49 \mathrm{~mm}$ chez les patients ayant une OG modérément à sévèrement augmentée de taille ( $\mathrm{p}<0,001)$. Davantage de patients dans le groupe ayant une dilatation de l'OG répondaient au principal critère d'évaluation (20\% contre 6\%; rapport de cotes 3,89; IC à 95\%: 1,32-11,43; $\mathrm{p}=0,0014)$. Conclusions: Une dilatation de l'OG (au moins modérée) est associée sur l'IRM à des infarctus aigus non lacunaires de multiples territoires vasculaires chez des patients ayant un AVC ischémique aigu ou un AIT sans FA connue ou diagnostic confirmé de FA. D'autres études sont nécessaires pour déterminer si cette population est susceptible de bénéficier d'un traitement anticoagulant.

Keywords: Stroke, cardioembolic stroke, left atrial dilatation, MRI, multiple vascular territory infarcts, cryptogenic doi:10.1017/cjn.2014.40

Can. J. Neurol. Sci. 2014; 41: 704-708

Atrial fibrillation (AF) is a common cause of stroke and transient ischemick attack (TIA) and is associated with stroke recurrence and multi-vessel territory cerebral infarct. ${ }^{1,2}$ Many patients have stroke of undetermined etiology despite a complete workup. ${ }^{3}$ Many of these cryptogenic strokes may in fact be due to concealed paroxystic AF and could potentially be treated with anticoagulation. ${ }^{4}$ Although prolonged monitoring may increase the diagnostic yield of AF, it is rarely performed and comes at a higher cost. ${ }^{5,6}$

The American College of Cardiology Foundation and the American Society of Echocardiography (ASE) rate transthoracic echocardiography (TEE) as a very appropriate test after a cerebrovascular event as it may disclose the source of the stroke. ${ }^{7}$ It is also useful in assessing left atrium (LA) size. ${ }^{8}$ Dilated LA is a well-known independent risk factor of both $\mathrm{AF}$ and stroke. ${ }^{9-14} \mathrm{~A}$ recent case-control study has found an odds ratio (OR) of 2,081 of having a stroke in patients with LA dilatation but sinusal rhythm

From the Department of Neurology (MSGB, JMB), Faculty of Medicine, Sherbrooke University, Sherbrooke; Charles-LeMoyne Hospital - Neurology (JMB,NL,LB) Charles-

LeMoyne Hospital - Cardiology (MB), Greenfield Park, Quebec, Canada. Received June 12, 2014. Final Revisions Submitted August 6, 2014. Correspondence to: Marie-Sarah Gagne Brosseau, Sherbrooke University - Neurology, Sherbrooke, Quebec, Canada, J1H 5N4. Email: marie-sarah.gagne.brosseau@usherbrooke.ca 
and preserved LV ejection fraction compared to normal LA size controls. ${ }^{15}$ Normal LA diameter values are $\leq 4.0 \mathrm{~cm}$ for men and $\leq 3,8$ for women. ${ }^{8}$

As increased LA size is a well established risk factor of AF and since AF correlates with multiple vascular territory strokes ${ }^{2}$, we sought to determine if a LA dilatation, defined as at least moderate, was associated with acute non lacunar multi-vessel territory infarct on magnetic resonance imaging (MRI) in a population of acute ischemic stroke (AIS) or TIA patients without known AF.

\section{Methods}

\section{Study Population}

All consecutive patients $\geq 18$ years of age who presented at Charles-LeMoyne Hospital emergency department with a suspected diagnosis of AIS or TIA, or suffering a AIS or TIA during hospitalization, between October 4th, 2006 and June 30th, 2011 were included in our study. All stroke and TIA cases seen at Charles-LeMoyne Hospital are prospectively entered in a computerized database. Charles-LeMoyne Hospital is a University affiliated hospital on the Montreal south shore, servicing a population of about 600000 . During the study period the urgent TIA had not yet been recognized and, therefore, most AIS and TIA seen at our hospital were evaluated in the emergency department.

Acute ischemic stroke and TIA were defined according to the World Health Organization definition. ${ }^{16}$ Patients were excluded from the final analysis if any of the following was present: final diagnosis other than AIS or TIA, MRI or transthoracic echocardiogram (TTE) not performed, LA diameter not mentioned on TTE report, previous history of AF or de novo diagnosis of AF within three months of the index event.

Demographics, medical history, medication, imaging data, stroke or TIA characteristics, National Institutes of Health Stroke Scale (NIHSS) and modified Rankin Scale (mRS) scores were recorded at baseline and at 90 day follow up, where all patients were seen at the stroke secondary prevention clinic. Orientation at discharge, as well as recurrence of vascular events (recurrent stroke or TIA, acute coronary syndrome and death) at three months, were also noted. All data were prospectively collected and entered into a standardized database. The analysis of the data and the design of the study, however, were retrospective. Brain MRI and cardiac investigations were therefore ordered at the treating physician's discretion. The study was approved by our local ethics committee.

\section{Brain MRI}

All brain MRIs were obtained on a 1.5 Tesla MRI system. All imaging was performed within seven days of symptoms onset, using a standard quadrature head coil. The protocol included sagittal, axial and coronal T1, axial T2, axial fluid-attenuated inversion recovery, axial diffuse-weighted imaging (DWI), apparent diffusion coefficient (ADC) and gradient echo sequences. A neurology resident (MSGB) and a stroke neurologist (JMB) blinded to the patient's medical history and TTE findings reviewed the MRI images. Another stroke neurologist (LB) reviewed cases for which a consensus was not initially obtained.

Infarct territories were divided into left carotid artery, right carotid artery and vertebrobasilar supply. Multiple vascular territory infarct was defined as an infarct involving $\geq$ two vascular territories and lacunar infarct was defined as subcortical area consistent with infarct measuring 3 to $15 \mathrm{~mm} .{ }^{17,18}$ Infarcts were considered acute when hyperintense on DWI and hypointense or isointense on ADC and chronic (old) if hyperintense on DWI and ADC. Acute and old non lacunar infarcts were also noted. Old infarcts (lacunar or not) were differentiated from leukoaraiosis as being hypointense on T1 images. White matter disease was graded using the Van Swieten scale. ${ }^{19}$

\section{Echocardiography}

All TTE were performed by cardiologists working at our hospital. Standard echocardiography was performed with Doppler studies (Philips, iE33 X Matrix echocardiography system) with a $3.5-\mathrm{MHz}$ multiphase array probe in subjects lying in a left lateral decubitus position. Left atrium measures were obtained by the biplane area-length method from two-dimensional echocardiography, based on the criteria of the ASE. ${ }^{8}$ Left atrium diameter was measured at the end-ventricular systole using M-Mode-two dimensional or anteroposterior linear dimension standard technique. $^{8}$

Although LA volume measurement better evaluates LA size than LA diameter measurement, we found that it was rarely performed at our hospital from 2006 until the end of 2010. We therefore used LA diameter measures for the current study. LA was defined as at least moderately dilated if the LA diameter was $\geq 47 \mathrm{~mm}$ for men and $\geq 43 \mathrm{~mm}$ for women. ${ }^{8}$ Left atrium volumes data were nevertheless collected when available and LA was defined as at least moderately dilated if the LA indexed volume (LA volume/body surface area) was $\geq 34 \mathrm{cc} / \mathrm{m}^{2}$ for both women and men ${ }^{8}$. The ellipsoid model or the Simpson's rule was used for LA volume estimates. Valvulopathies were noted if graded as at least moderate. Left ventricular ejection fraction values were also collected.

\section{Outcomes}

The primary outcome was acute non lacunar multi-vessel territory infarct(s) on a brain MRI performed within seven days of symptom onset.

Other MRI outcomes included: all acute ischemic infarct(s), acute lacunar infarct(s), acute non lacunar infarct(s), old non lacunar infarct(s) and significant white matter disease defined as a Van Swieten scale $>4$. The following 90-day clinical outcomes were also analysed: death, mRS $0-1$, recurrent symptomatic cerebral infarct confirmed by computed tomography scan or MRI, recurrent TIA, acute coronary syndrome (ACS) and the composite outcome of infarct, TIA, ACS or death. Acute coronary syndrome was defined according to guidelines. ${ }^{20}$

\section{Statistical analysis}

Statistical analysis was performed using the SPSS 17.0 software. Continuous variables were expressed in means with standard deviations (symmetrical data) or median values (skewed data). The Fisher exact test and the Pearson Chi-square test were used to evaluate categorical variables. A multivariable analysis using multiple logistical regressions was performed for all variables significant in the univariable analysis (hypertension, coronary artery disease, previous stroke or TIA, baseline NIHSS, 
and akinetic area on TTE) and also for other potentially confounding variables (medication, age, diabetes, hyperlipedemia, heart failure, smoking, baseline blood pressure, baseline glucose and systolic ejection fraction). Odds ratio (OR) with $95 \%$ confidence interval (CI) were calculated for the primary as well as secondary outcomes. P values $<0.05$ were considered statistically significant.

\section{RESULTS}

From October $4^{\text {th }} 2006$ to June $30^{\text {th }} 2011,1593$ patients were seen with a suspected diagnosis of AIS or TIA. Of these, 1237 were excluded for the following reasons: 43 had a prior history of $\mathrm{AF}$ or a de novo diagnosis of $\mathrm{AF}$ (or in the three months following the index event), 1009 did not have an MRI (of which 173 had prior AF), 53 had no TTE or no LA diameter measurement on TTE and 132 had a final diagnosis other than AIS or TIA. Three hundred and fifty six patients were therefore included in the final analysis. Excluding patients with prior or de novo AF (as LA dilatation is already known to be associated with AF), the baseline characteristics were similar between patients excluded from, and included in, the final analysis.

Seven percent $(25 / 356)$ of the study population had a dilated LA according to our definition (LA diameter $\geq 47 \mathrm{~mm}$ for men and $\geq 43 \mathrm{~mm}$ for women). These patients had more hypertension, coronary artery disease, previous stroke or TIA, akinetic areas on TTE, higher baseline NIHSS and were more prone to be using antihypertensive medication. (Table 1) The median MRI delay was identical in both groups (two days). The main outcome of acute non lacunar multi-vessel territory infarct(s) on MRI was seen in $20 \%$ of the LA dilatation population compared to $6 \%$ of the control group (OR 3.89; 95\% CI 1.32-11.43; $\mathrm{p}=0.014$ ). (Table 2) This remained significant after the multivariable analysis $(p=0.035)$. No difference was observed in the left atrial dilatation group between those taking antiplatelets at baseline (3/14) and those not taking them (4/11) in regards to the primary outcome but the number of patients was small (OR $0.48 ; 95 \% \mathrm{CI}$ 1.0.08-2.80; $\mathrm{p}=0.41)$. An association was observed between LA dilatation and old lacunar infarct $(76.0 \%$ vs $48.3 \%$; OR $3.38 ; 95 \%$ CI $1.38-8.69 ; \mathrm{p}=0.011)$ and was of borderline significance between LA dilatation and old non lacunar infarcts (OR 2.67; 95\% CI 1.00-7.13; $\mathrm{p}=0.050)$. As $\mathrm{AF}$ cases were excluded, proven cardioembolic cases were rare in this study but the presumed stroke etiologies were similar between the normal vs dilated LA groups: large artery (13\% vs $16 \%$ respectively; $\mathrm{p}=0.757)$, small vessels $(28.9 \%$ vs $28.0 \%$ respectively; $\mathrm{p}=0.823)$, cardioembolic $(0.6 \%$ vs $0 \%$ respectively; $\mathrm{p}=1.000)$, other determined etiology $(0.9 \%$ vs $0 \%$ respectively; $\mathrm{p}=1.000)$ and undetermined etiology $(61.6 \%$ vs $56 \%$ respectively; $\mathrm{p}=0.731)$. Interestingly, acute non lacunar multi-vessel territory infarct(s) on MRI was more frequent in cryptogenic stroke/TIA with LA dilatation (5/14) than with normal LA diameter (20/204) $(35.7 \%$ vs $9 \%$; OR $5.11 ; 95 \%$ CI 1.56-17.74; $\mathrm{p}=0.007 ; \mathrm{p}=0.024$ multivariable analysis).

No patient was lost to follow up at 90 days. Three-month clinical outcomes other than the mRS were similar between groups (Table 3). Fewer patients with an enlarged LA had good clinical outcome compared to the control group (32.0\% vs $60.4 \%$; OR $0.31 ; 95 \%$ CI $0.13-0.73 ; \mathrm{p}=0.008$ ) but this difference did not reach statistical significance after multivariable analysis $(\mathrm{p}=0.068)$. A trend toward more recurrent stroke and TIA was
Table 1: Baseline characteristics

\begin{tabular}{|c|c|c|c|}
\hline & $\begin{array}{c}\text { Normal and } \\
\text { mildly } \\
\text { dilated LA } \\
\mathbf{n}=\mathbf{3 3 1}\end{array}$ & $\begin{array}{l}\text { Moderately } \\
\text { and severely } \\
\text { dilated LA* } \\
\quad \mathbf{n}=\mathbf{2 5}\end{array}$ & p value \\
\hline Age, years (mean) & $65.5 \pm 5.5$ & $65.4 \pm 5.5$ & 0.988 \\
\hline Male sex, n (\%) & $192(58.0)$ & $17(68.0)$ & 0.443 \\
\hline Acute ischemic stroke, $\mathrm{n}(\%)$ & $278(84.0)$ & $22(88.0)$ & 0.779 \\
\hline Dementia, n (\%) & $10(3.0)$ & $0(0)$ & 1.000 \\
\hline Hypertension, n (\%) & $193(58.3)$ & $21(84.0)$ & 0.011 \\
\hline Diabetes, n (\%) & $81(24.5)$ & $6(24.0)$ & 0.958 \\
\hline Hyperlipemia, n (\%) & $159(48.0)$ & $16(64.0)$ & 0.183 \\
\hline $\mathrm{CAD}, \mathrm{n}(\%)$ & $61(18.4)$ & $13(52.0)$ & $<0.001$ \\
\hline Heart failure, n (\%) & $5(1.5)$ & $1(4.0)$ & 0.356 \\
\hline Previous stroke or TIA, n (\%) & $58(17.5)$ & $11(44.0)$ & 0.003 \\
\hline Smoking, n (\%) & $105(31.7)$ & $5(20.0)$ & 0.267 \\
\hline Alcohol abuse, n (\%) & $24(7.2)$ & $1(4.0)$ & 1.000 \\
\hline Baseline NIHSS (median) & 2 & 4 & 0.045 \\
\hline $\begin{array}{l}\text { Prior to stroke-TIA Modified } \\
\text { Rankin scale (median) }\end{array}$ & 0 & 0 & 0.167 \\
\hline $\begin{array}{l}\text { Baseline systolic } \mathrm{BP}, \mathrm{mmHg} \\
\quad(\text { mean })\end{array}$ & $158.9 \pm 17$ & $156.9 \pm 14$ & 0.872 \\
\hline $\begin{array}{l}\text { Baseline diastolic } \mathrm{BP}, \mathrm{mmHg} \\
\quad(\text { mean })\end{array}$ & $88.4 \pm 12$ & $82.9 \pm 11$ & 0.528 \\
\hline $\begin{array}{l}\text { Baseline glucose, } \mathrm{mmol} / \mathrm{L} \\
(\text { mean })^{* *}\end{array}$ & $8.14 \pm 3.5$ & $6.98 \pm 2.4$ & 0.488 \\
\hline Treatment with rTPA, n (\%) & $13(3.9)$ & $2(8.0)$ & 0.079 \\
\hline Antiplatelets, n (\%) & $131(39.6)$ & $14(56.0)$ & 0.161 \\
\hline Anticoagulants, n (\%) & $5(1.5)$ & $1(4.0)$ & 0.356 \\
\hline Antihypertensive, n (\%) & $156(47.1)$ & $19(76.0)$ & 0.010 \\
\hline Statins, n (\%) & $116(35.0)$ & $14(56.0)$ & 0.060 \\
\hline $\begin{array}{l}\text { Systolic ejection fraction, } \% \\
\text { (median) }\end{array}$ & 62 & 60 & 0.251 \\
\hline Akinetic area on TTE, n (\%) & $33(10.0)$ & $8(32.0)$ & 0.003 \\
\hline Left atrium diameter, mm (mean) & 37 & 49 & $<0.001$ \\
\hline Moderate or severe Valvulopathy & $22(6.6)$ & $4(16.0)$ & 0.098 \\
\hline Large artery stenosis $>50 \%, \mathrm{n}(\%)$ & $43(13.0)$ & $4(16.0)$ & 0.757 \\
\hline $\begin{array}{l}\geq 24 \text { hours Holter or } \geq 24 \mathrm{~h} \text { heart } \\
\text { monitoring }\end{array}$ & $312(94.3)$ & $25(100)$ & 0.382 \\
\hline Aortic arch plaque $>4 \mathrm{~mm}$ & $6(1.8)$ & $1(4)$ & 0.402 \\
\hline
\end{tabular}

$\mathrm{CAD}=$ coronary artery disease $\mathrm{BP}=$ blood pressure $; \mathrm{LA}=$ left atrium; TIA $=$ transient ischemic attack; $\mathrm{rTPA}=$ recombinant tissue plasminogen activator; NIHSS $=$ National Institutes of Health Stroke Scale; TTE = transthoracic echocardiogram.

*Left atrium was defined as at least moderately dilated using LA diameter $\geq 47 \mathrm{~mm}$ for men and $\geq 43 \mathrm{~mm}$ for women.

**Glucose upon emergency room arrival (non fasting).

seen among the enlarged LA size population but did not achieve statistical significance.

Sixty-nine patients had LA indexed volume measurements; of which six patients had LA dilatation defined as at least moderate. A multiple vascular territory infarct on MRI was 
Table 2: Magnetic resonance imaging outcomes

\begin{tabular}{|c|c|c|c|c|c|}
\hline & $\begin{array}{l}\text { Normal and mildly dilated LA } \\
\qquad \mathrm{n}=331\end{array}$ & $\begin{array}{l}\text { Moderately and severely dilated LA } \\
\qquad \mathrm{n}=\mathbf{2 5}\end{array}$ & Odds ratio & $95 \% \mathrm{CI}$ & p value \\
\hline Multi-vessel territory acute non lacunar infarct, n (\%) & $20(6.0)$ & $5(20.0)$ & 3.89 & $1.32-11.43$ & 0.014 \\
\hline Acute ischemic infarct (all types), $\mathrm{n}(\%)$ & $257(77.6)$ & $21(84.0)$ & 1.51 & $0.50-4.54$ & 0.462 \\
\hline Acute lacunar infarct, $\mathrm{n}(\%)$ & $79(28.9)$ & $7(28.0)$ & 1.24 & $0.50-3.09$ & 0.642 \\
\hline Single-vessel territory acute non lacunar infarct, $\mathrm{n}(\%)$ & $158(47.7)$ & $9(36.0)$ & 0.62 & $0.26-1.43$ & 0.261 \\
\hline Old non lacunar infarct, n (\%) & 35 (10.6) & $6(24.0)$ & 2.67 & $1.00-7.13$ & 0.050 \\
\hline Old lacunar infarct, n (\%) & $160(48.3)$ & $19(76.0)$ & 3.38 & $1.32-8.69$ & 0.011 \\
\hline Van Swieten score $>4, \mathrm{n}(\%)$ & $74(22.4)$ & $7(28.0)$ & 1.35 & $0.54-3.336$ & 0.518 \\
\hline
\end{tabular}

$\mathrm{LA}=$ left atrium; $\mathrm{CI}=$ confidence interval.

Table 3: 90-day clinical outcomes

\begin{tabular}{|c|c|c|c|c|c|}
\hline & $\begin{array}{l}\text { Normal and mildly } \\
\text { dilated LA } \\
\mathbf{n}=\mathbf{3 3 1}\end{array}$ & $\begin{array}{c}\text { Moderately and severely } \\
\text { dilated LA } \\
n=25\end{array}$ & Odds Ratio & $95 \% \mathrm{CI}$ & p value \\
\hline Death, n (\%) & $26(7.8)$ & $3(12.0)$ & 1.60 & $0.45-5.70$ & 0.469 \\
\hline Modified Rankin Score 0-1, n (\%) & $200(60.4)$ & $8(32.0)$ & 0.31 & $0.13-0.73$ & 0.008 \\
\hline Recurrent symptomatic ischemic stroke, n (\%) & $14(4.2)$ & $2(8.0)$ & 1.97 & $0.42-9.19$ & 0.389 \\
\hline Recurrent or new TIA, n (\%) & $13(3.9)$ & $2(8.0)$ & 2.13 & $0.45-10.00$ & 0.339 \\
\hline Recurrent or new TIA or ischemic stroke, n $(\%)$ & $27(8.2)$ & $4(16.0)$ & 2.14 & $0.69-6.70$ & 0.189 \\
\hline Acute coronary syndrome, $\mathrm{n}(\%)$ & $1(0.3)$ & $0(0)$ & 4.32 & $0.17-108.77$ & 0.374 \\
\hline Death, recurrent stroke and acute coronary syndrome, $\mathrm{n}(\%)$ & $41(12.4)$ & $5(20.0)$ & 1.77 & $0.63-4.97$ & 0.280 \\
\hline
\end{tabular}

$\mathrm{TIA}=$ transient ischemic attack; $\mathrm{LA}=$ left atrium; $\mathrm{CI}=$ confidence interval .

observed in 2/6 patients (33\%) with increased LA indexed volume compared to $3 / 63$ patients $(4.8 \%)$ in the control population $(\mathrm{p}=0.057)$. Too few patients had LA indexed volume measurements to perform any conclusive secondary outcome analysis.

\section{DISCUSSION}

We found that, in a population of AIS and TIA without known or diagnosed AF, acute non lacunar multiple territory acute infarct(s) on MRI was more common in those with at least moderate LA dilatation, even after multivariable analyses. This association was also seen in those with cryptogenic stroke/TIA. Our results are consistent with the known association between LA dilatation and cerebrovascular events as well as LA dilatation and AF. ${ }^{9-14}$

AF is identified in about $20 \%$ of stroke patients but, after an extensive workup, as many as 30-40\% of strokes remain without any identified cause. ${ }^{21}$. These so called cryptogenic strokes have many potential causes, including concealed paroxystic. Occult cardiac embolism was considered a major mechanism of cryptogenic stroke in the Stroke Data Bank. ${ }^{22}$ Moreover, in a study that assessed longer-term cardiac rhythm monitoring using an outpatient telemetry system for a median duration of 21 days among 56 patients with cryptogenic stroke, paroxysmal AF was detected in 13 patients $(23 \%){ }^{23}$ The median time to detection of $\mathrm{AF}$ was seven days. Outside of study protocols, prolonged monitoring is costly and difficult to implement in primary and secondary care facilities. For this reason, a simple echocardiographic marker that identifies stroke and TIA patients at higher risk of AF would be useful in selecting patients that would benefit most from additional cardiac rhythm testing. Identification of a cut-off LA diameter associated with multi-vessel territory acute infarct(s) is a simple tool that may allow neurologists and hospitalist physicians to identify patients at high risk of AF. Stroke or TIA in association with enlarged LA may in some cases be caused by mechanisms other than AF: blood stasis in the LA, associated valvulopathy, etc. $15,24,25$

Our study has some limitations. First, even if all data were prospectively entered in a standardized database, the design of the study was retrospective. One has to consider the large number of patients excluded, mainly because they did not have an MRI. Although baseline characteristics were similar between the "excluded" population and the included population, retrospective biases are still possible. Furthermore, cardiac investigations were ordered at the discretion of the treating physicians and some $\mathrm{AF}$ could have been missed, especially in the control group as $5.7 \%$ did not have a Holter or $\geq 24 \mathrm{~h}$ heart monitoring. Nevertheless all patients in the dilated LA group had at least 24-hour Holter monitoring and an electrocardiogram, therefore this should not have influenced our results. Second, this is a single-center study. Third, the American Society of Echocardiography states that LA volume determinations are preferred over linear dimensions because they allow more accurate assessment of the asymmetric remodeling of the LA chamber. ${ }^{8}$ However, we used LA diameter values because they were more easily available at our center. 
Again, there is no evidence to suggest that our results would have been different if we had used LA volume. In fact, the relationship between multiple territory stroke and LA size might have been stronger, as LA volume is a better estimate of the LA chamber size than LA diameter. Also, we used relatively conservative estimates of left atrial dimensions. Such an approach is more specific than sensitive. Nevertheless, we did perform an analysis (data not shown here) using normal left atrial cases vs all others (including mildy dilated left atrial cases) and the results were not significant. Finally, even though aortic arch atheroma was evaluated, TTE is not as sensitive as TEE to identify it and we may have underestimated the real frequency of aortic arch plaques $>4 \mathrm{~mm}$. On the other hand, no statistically significant difference was identified between the two groups.

\section{ConClusions}

In conclusion, our study showed that, in a population of AIS or TIA without known or diagnosed AF, a moderate or severe LA dilatation is associated with acute non lacunar multiple territory stroke(s) on MRI. Further studies are necessary to confirm this finding and to determine if this population might benefit from anticoagulation.

\section{ACKNOWLEDGMENTS}

The authors thank Martine Minville, Lise Blais, Christel Simard and Johanne Pontbriand.

\section{Disclosures}

The authors have no conflicts of interest to declare.

\section{REFERENCES}

1. Petersen P, Pedersen F, Madsen EB, Brun B, Gyldensted C, Boysen G. Echocardiography and cerebral computed tomography in chronic atrial fibrillation. Eur Heart J. 1989;10:1101-4.

2. Kang DW, Chalela JA, Ezzeddine MA, Warach S. Association of ischemic lesion patterns on early diffusion-weighted imaging with TOAST stroke subtypes. Arch Neurol Psychiatry. 2003;60:1730-4.

3. Adams HP Jr., Bendixen BH, Kappelle LJ, et al. Classification of subtype of acute ischemic stroke. Definitions for use in a multicenter clinical trial. TOAST. Trial of Org 10172 in Acute Stroke Treatment. Stroke. 1993;24:35-41.

4. Hart RG, Pearce LA, Rothbart RM, McAnulty JH, Asinger RW, Halperin JL. Stroke with intermittent atrial fibrillation: incidence and predictors during aspirin therapy. Stroke Prevention in Atrial Fibrillation Investigators. J Am Coll Cardiol. 2000;35:183-7.

5. Liao J, Khalid Z, Scallan C, Morillo C, O'Donnell M. Noninvasive cardiac monitoring for detecting paroxysmal atrial fibrillation or flutter after acute ischemic stroke: a systematic review. Stroke. 2007;38:2935-40.

6. Elijovich L, Josephson SA, Fung GL, Smith WS. Intermittent atrial fibrillation may account for a large proportion of otherwise cryptogenic stroke: a study of 30-day cardiac event monitors. J Stroke Cerebrovasc Dis. 2009;18:185-9.

7. Douglas PS, Khandheria B, Stainback RF, et al. ACCF/ASE/ACEP/ ASNC/SCAI/SCCT/SCMR 2007 appropriateness criteria for transthoracic and transesophageal echocardiography: a report of the American College of Cardiology Foundation Quality Strategic Directions Committee Appropriateness Criteria Working Group, American Society of Echocardiography, American College of Emergency Physicians, American Society of Nuclear Cardiology,
Society for Cardiovascular Angiography and Interventions, Society of Cardiovascular Computed Tomography, and the Society for Cardiovascular Magnetic Resonance endorsed by the American College of Chest Physicians and the Society of Critical Care Medicine. J Am Coll Cardiol. 2007;50:187-204.

8. Lang RM, Bierig M, Devereux RB, et al. Recommendations for chamber quantification: a report from the American Society of Echocardiography's Guidelines and Standards Committee and the Chamber Quantification Writing Group, developed in conjunction with the European Association of Echocardiography, a branch of the European Society of Cardiology. J Am Soc Echocardiog. 2005;18:1440-63.

9. Benjamin EJ, D'Agostino RB, Belanger AJ, Wolf PA, Levy D. Left atrial size and the risk of stroke and death. The Framingham Heart Study. Circulation. 1995;92:835-41.

10. Di Tullio MR, Sacco RL, Sciacca RR, Homma S. Left atrial size and the risk of ischemic stroke in an ethnically mixed population. Stroke. 1999;30:2019-24.

11. Flaker GC, Fletcher KA, Rothbart RM, Halperin JL, Hart RG. Clinical and echocardiographic features of intermittent atrial fibrillation that predict recurrent atrial fibrillation. Stroke Prevention in Atrial Fibrillation (SPAF) Investigators. Am J Cardiol. 1995;76:355-8.

12. Tsang TS, Barnes ME, Bailey KR, et al. Left atrial volume: important risk marker of incident atrial fibrillation in 1655 older men and women. Mayo Clin Proc. 2001;76:467-75.

13. Vaziri SM, Larson MG, Benjamin EJ, Levy D. Echocardiographic predictors of nonrheumatic atrial fibrillation. The Framingham Heart Study. Circulation. 1994;89:724-30.

14. Barnes ME, Miyasaka Y, Seward JB, et al. Left atrial volume in the prediction of first ischemic stroke in an elderly cohort without atrial fibrillation. Mayo Clin Proc. 2004;79:1008-14.

15. Kim BS, Lee HJ, Kim JH, et al. Relationship between left atrial size and stroke in patients with sinus rhythm and preserved systolic function. Korean J Intern Med. 2009;24:24-32.

16. The World Health Organization MONICA Project (monitoring trends and determinants in cardiovascular disease): a major international collaboration. WHO MONICA Project Principal Investigators. J Clin Epidemiol. 1988;41:105-14.

17. Fisher CM. Lacunes: Small, deep cerebral infarcts. Neurology. 2011;77:2104.

18. Pantoni L. Cerebral small vessel disease: from pathogenesis and clinical characteristics to therapeutic challenges. Lancet Neurol. 2010;9:689-701.

19. Van Swieten JC, Hijdra A, Koudstaal PJ, van Gijn J. Grading white matter lesions on CT and MRI: a simple scale. J Neurol Neurosurg Psychiatry. 1990;53:1080-3.

20. Anderson JL, Adams CD, Antman EM, et al. 2011 ACCF/ AHA Focused Update Incorporated Into the ACC/AHA 2007 Guidelines for the Management of Patients With Unstable Angina/Non-ST-Elevation Myocardial Infarction: a report of the American College of Cardiology Foundation/American Heart Association Task Force on Practice Guidelines. Circulation. 2011;123:426-579.

21. Kolominsky-Rabas PL, Weber M, Gefeller O, Neundoerfer B, Heuschmann PU. Epidemiology of ischemic stroke subtypes according to TOAST criteria: incidence, recurrence, and longterm survival in ischemic stroke subtypes: a populationbased study. Stroke. 2001;32:2735-40.

22. Sacco RL, Ellenberg JH, Mohr JP, et al. Infarcts of undetermined cause: the NINCDS Stroke Data Bank. Ann Neurol. 1989;25:382-90.

23. Tayal AH, Tian M, Kelly KM, et al. Atrial fibrillation detected by mobile cardiac outpatient telemetry in cryptogenic TIA or stroke. Neurology. 2008;71:1696-701.

24. Lee RJ, Bartzokis T, Yeoh TK, Grogin HR, Choi D, Schnittger I. Enhanced detection of intracardiac sources of cerebral emboli by transesophageal echocardiography. Stroke. 1991;22:734-9.

25. Daniel WG, Nellessen U, Schroder E, et al. Left atrial spontaneous echo contrast in mitral valve disease: an indicator for an increased thromboembolic risk. J Am Coll Cardiol. 1988;11:1204-11. 